\title{
БЕНЗОАЗАКРАУН-ЭФИРЫ: НОВЫЕ ЭФФЕКТИВНЫЕ ХЕЛАТОРЫ ДЛЯ РАДИОНУКЛИДОВ
}

\author{
А.В. Пашанова, ${ }^{1,2}$, А.Д. Зубенко', Е.В. Матазова, Б.В. Егорова ${ }^{3}$, \\ О.А. Федорова ${ }^{1,2}$
}

${ }^{1}$ Институт элементоорганических соединений им. А. Н. Несмеянова, 119991, Россия, Москва, ул. Вавилова, 28.

${ }^{2}$ Российский химико-технологический университет им. Д. И. Менделеева, 125047, Россия, Москва, Миусская площадь, 9.

${ }^{3}$ Московский государственный университет им. М.В. Ломоносова, Химический факультет, 119991, Россия, Москва, Ленинские горы, д. 1, стр. 3.

DOI: 10.19163/MedChemRussia2021-2021-130

E-mail:1404an99@mail.ru

В последние десятилетия разработка новых хелаторов и получение радиофармпрепаратов на их основе является крайне актуальной задачей ядерной медицины. Применяющиеся в настоящее время хелаторы DOTA и DTPA имеют ряд недостатков, таких как медленная кинетика комплексообразования или неустойчивость комплексов [1]. В связи с этим, целью данной работы является разработка новых хелаторов с оптимальными свойствами для их применения в радиофармацевтике. Нами были предложены комплексоны на основе бензоазакраун-эфиров, содержащих дополнительные хелатирующие группы.

Для синтезированных соединений методом потенциометрического титрования были получены следующие константы устойчивости комплексов:

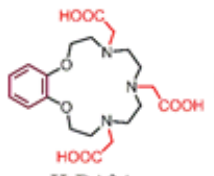

$\mathrm{H}_{3} \mathrm{BA} 3 \mathrm{~A}$

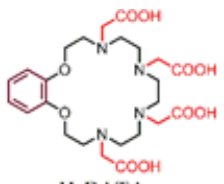

$\mathrm{H}_{4} \mathrm{BATA}$

\begin{tabular}{|l|l|l|l|l|l|}
\hline \multirow{2}{*}{ Лиганд } & \multicolumn{5}{|c|}{ lgK } \\
\cline { 2 - 6 } & $\mathbf{C u 2 +}$ & Pb2+ & Sc3+ & Y3+ & Bi3+ \\
\hline H3BA3A & 18,4 & 14,0 & 14,2 & 11,4 & 26,9 \\
\hline H4BATA & 23,9 & 22,3 & 21,17 & 17,4 & 32,5 \\
\hline
\end{tabular}

Для лиганда $\mathrm{H}_{4}$ ВАТА была проведена серия исследований для определения возможности применения как компонента радиофармпрепаратов с ${ }^{213,212} \mathrm{Bi}$. Показано, что 97-99\% катиона связывается менее чем за минуту при комнатной температуре.

В исследованиях меченых соединений in vitro установлено, что комплекс $\mathrm{BATA} \bullet \mathrm{Bi}^{3+}$ обладает высокой стабильностью, а также демонстрирует эффективное выведение и отсутствие диссоциации комплекса в условиях in vivo.

Таким образом, $\mathrm{H}_{4}$ ВАТА является идеальным хелатором для получения на его основе конъюгатов с биомолекулами и создания терапевтических радиофармпрепаратов, содержащих короткоживущие изотопы висмута.

Работа выполнена при финансовой поддержке Российского научного фонда (проект № 18-73-10035).

\section{Литература}

[1] E. V. Matazova, B. V. Egorova, E. A. Konopkina et al. Med. Chem. Commun., 2019, 10, 1641-1645. 